\title{
Faktor Yang Berhubungan Dengan Motivasi lbu Hamil Trimester Tiga Dalam Melaksanakan Inisiasi Menyusu Dini (IMD) di Puskesmas Kecamatan Medan Denai
}

\author{
Ika Nopa \\ Universitas Muhammadiyah Sumatera Utara \\ J1. Kapten mukhtar basri medan 061-6619056 \\ Email : dr.ikanopanst@gmail.com \\ Diterima : 20 April 2019. Perbaikan : 5 Mei 2019. Diterbitkan : 29 Juni 2019 \\ DOI : https://doi.org/10.22219/sm.Vol15.SMUMM1.8483
}

\begin{abstract}
ABSTRAK
Inisiasi menyusu dini (IMD) merupakan salah satu usaha dalam menurunkan angka kematian neonatus dan menentukan keberhasilan ASI eksklusif. Cakupan Inisiasi Menyusu Dini (IMD) dan ASI eksklusif di Indonesia masih rendah. Untuk meningkatkan cakupan pemberian Inisiasi Menyusu Dini (IMD) dan ASI eksklusif maka diperlukan motivasi ibu. Untuk itu perlu diketahui factor yang berhubungan dengan motivasi ibu dalam melakukan Inisiasi Menyusu Dini (IMD). Penelitian ini merupakan penelitian deskriptif analitik dengan desain cross sectional study untuk mengetahui variable individu yang berhubungan dengan motivasi ibu dalam memberikan ASI eksklusif pada ibu hamil trimester tiga di puskesmas kecamatan medan denai. Pengumpulan data mengunakan teknik wawancara terstruktur dengan kuesioner yang telah divalidasi sebelumnya.Data kemudian dianalisis menggunakan program SPSS dengan cby square sebagai uji hipotesis. Hasil penelitian dari variabel individu yang diteliti didapati ada hubungan yang bermakna antara variabel tingkat pengetahuan ( $\mathrm{p}: 0,004)$ dan paritas ( 0 ,011) terhadap motivasi ibu dan tidak ada hubungan yang bermakna antara variabel usia ( $p$ 0.133), pendidikan ( $p$ 0.310) dan pekerjaan ( $p$ 0.298) terhadap motivasi ibu dalam melaksanakan Inisiasi Menyusu Dini (IMD).
\end{abstract}

Kata Kunci : Ibu Hamil, Faktor, Inisiasi Menyusu Dini (IMD) 


\begin{abstract}
Early breastfeeding initiation is an effort to reduce neonatal mortality rate and to increase achievement of breastfeeding program targets. The coverage of Early Breastfeeding Initiation and exclusive breastfeeding in Indonesia is still low. To increase the coverage of early breastfeeding initiation and exclusive breastfeeding, mother's motivation is needed. For this reason, it is necessary to know the factors that related to the mother's motivation in carrying out Early Breastfeeding Initiation This study is an descriptive analytical study with a cross sectional study design to determine individual variables related to motivation of mothers to initiate early breastfeeding. The sample in this study was third trimester pregnant women in Puskesmas Medan Denai. Data collected using structured interview with validated questionnaires. Then the data is analyzed using the SPSS program with chy square as a hypothesis test. The results of this study were found a significant relationship between knowledge ( $p$ : $0.004)$ and parity $(p$ 0.011) on l motivation in carrying out Early Breastfeeding Initiation. T-There was no significant relationship between age variables ( $p 0.133)$, education $(p 0.310)$ and employment $(p 0.298)$ on motivation in carrying out Early Breastfeeding Initiation
\end{abstract}

Key Words : Pregnant mother, Related Factor, Early Breastfeeding Initiation

\title{
PENDAHULUAN
}

Angka kematian neonatur merupakan salah satu indikator dalam menilai kesehatan masyarakat. Angka Kematian Neonatus di Indonesia pada tahun 2015 sebesar 19 bayi per 1000 kelahiran hidup (Kemenkes RI., 2017).

Dunia dengan Sustainable Development Goals (SDGs) menargetkan kan penurunan angka kematian neonatus di bawah 12 bayi per 1000 kelahiran hidup. Dari 195 negara yang dianalisis didapati 118 negara telah mencapai target Sustainable Development Goals (SDGs) dan 51 negara diharapkan dapat mencapai target pada tahun 2030 dan salah satunya adalah Indonesia (Unicef, 2017).

Inisiasi Menyusu Dini (IMD) adalah pemberian Air Susu Ibu (ASI) segera setelah bayi lahir. Inisiasi menyusu dini (IMD) merupakan salah satu usaha dalam menurunkan angka kematian neonatus. Pada salah satu penelitian di Ghana didapati bahwa menunda Inisiasi Menyusu Dini (IMD) dapat meningkatkan resiko kematian pada neonatus. Semakin menunda Inisiasi Menyusu Dini maka resiko kematian neonatus pun semakin meningkat (Edmond et al., 2006).

Inisiasi Menyusu Dini (IMD) juga merupakan salah satu faktor yang menentukan keberhasilan dalam memberikan ASI eksklusif. Dari hasil penelitian didapati Inisiasi Menyusu Dini (IMD) meningkatkan keberhasilan pemberian ASI. eksklusif sebanyak 8 kali lebih besar (Fikawati S. \& Syafiq A., 2010).

World Health Organization (WHO) merekomendasikan untuk IMD sesegera mungkin dalam satu jam setelah persalinan untuk menurunkan angka kematian bayi dan mendukung ASI eksklusif, (WHO \& UNICEF., 2018) Hasil penelitian tentang faktor yang mempengaruhi kegagalan dalam memberikan ASI eksklusif didapati tidak melakukan Inisiasi Menyusu Dini berkontribusi terhadap kegagalan dalam memenerikan ASI eksklusif (Suryani D et al., 2017).

Selain itu IMD juga memberikan manfaat bagi ibu yakni dapat menurunkan stress fisiologis yang terjadi pada ibu pasca melahirkan yang diketahui melalui kadar kortisol. (Bigelow A. et al. 
2012) Di Indonesia hanya 51,3 \% bayi baru lahir yang mendapatkan IMD dan hanya 35,7\% bayi yang mendapat ASI eksklusif pada tahun 2017. Sementara di Sumatra Utara hanya 38,7 \% bayi yang mendapat Inisiasi Menyusu Dini (IMD) dan hanya 10,7 \% bayi yang mendapat ASI eksklusif pada tahun 2017 (Direktorat Gizi Masyarakat DitJen KesMas, 2018).

Hasil penelitian menunjukkan adanya hubungan antara motivasi ibu dengan pelaksanaan Inisiasi Menyusu Dini (IMD) (Rompis O. et al., 2017). Untuk meningkatkan cakupan pemberian Inisiasi Menyusu Dini (IMD) dan ASI eksklusif maka diperlukan motivasi ibu dalam memberikan Inisiasi Menyusu Dini. Untuk itu perlu diketahui faktor yang berhubungan dengan motivasi ibu dalam melakukan Inisiasi Menyusu Dini (IMD).

\section{METODE}

Penelitian ini merupakan penelitian analitik dengan desain cross sectional study. Sampel pada penelitian ini adalah ibu hamil trimester tiga di Puskesmas Kecamatan Medan Denai. Penarikan sampel menggunakan teknik total sampling dan didapati 50 orang ibu hamil trimester. Teknik pengumpulan data dengan wawancara terstruktur. Dimana setiap responden ditanya sesuai kuesioner yang sudah divalidasi sebelumnya. Variabel yang diteliti adalah variabel individu yakni usia, paritas, pendidikan, pekerjaan dan tingkat pengetahuan tentang Inisiasi Menyusu Dini (IMD). Data yang terkumpul kemudian dianalisis meliputi analisis univariat dan analisis bivariate dengan SPSS dan menggunakan chy squre sebagai uji statistik.

\section{HASIL DAN PEMBAHASAN}

Analisis univariat dilakukan untuk mengetahu karakteristik dan frekuensi variable yang diamati

Tabel 1 Distribusi frekuensi variabel yang diteliti

\begin{tabular}{ccc}
\hline Variabel & Kategori & Frekuensi N (\%) \\
\hline Usia & $20-34$ tahun & $47(94)$ \\
\hline Paritas & $\geq 35$ tahun & $3(6)$ \\
\hline & 1 & $26(52)$ \\
\hline Pendidikan & Dasar & $24(48)$ \\
\hline & Menengah & $40(80)$ \\
\hline Pekerjaan & Tidak bekerja & $39(78)$ \\
\hline
\end{tabular}




\begin{tabular}{ccc}
\hline & Bekerja & $11(22)$ \\
\hline Pengetahuan & Baik & $33(66)$ \\
\hline & Kurang Baik & $17(34)$ \\
\hline Motivasi & Kuat & $26(52)$ \\
\hline & Lemah & $24(48)$
\end{tabular}

Dari hasil penelitian didapati karakteristik terbanyak berusia 20-34, masih dalam usia yang tidak beresiko untuk terjadi komplikasi dalam kehamilan, kategori pendidikan yang terbanyak adalah pendidikan menengah yakni SMA atau SMK, kategori pekerjaan yang terbanyak adalah tidak bekerja atau berstatus sebagai ibu rumah tangga, kategori paritas yang terbanyak adalah kehamilan pertama, dan kategori pengetahuan yang terbanyak adalah pengetahuan baik. Sementara untuk motivasi, sebagian besar responden memiliki motivasi yang kuat untuk melakukan inisiasi menyusu dini saat melahirkan.

Analisis bivariat

Analisis bivariat dilakukan untuk mengetahui hubungan masing masing variabel independent yakni variable individu (usia, paritas, pendidikan, pekerjaan dan tingkat pengetahuan) terhadap motivasi ibu hamil dalam melakukan Inisiasi Menyusu Dini.

Tabel 2. Hubungan variable individu terhadap motivasi melakukan Inisiasi Menyusu Dini (IMD)

\begin{tabular}{|c|c|c|c|c|}
\hline \multirow[t]{2}{*}{ Variabel } & \multirow[t]{2}{*}{ Kategori } & \multicolumn{2}{|c|}{ Motivasi IMD } & \multirow[t]{2}{*}{$\mathrm{P}$ value } \\
\hline & & Kuatn \% & Lemahn $\%$ & \\
\hline \multirow{4}{*}{ Usia } & \multirow{2}{*}{$20-34$} & 23 & 24 & \multirow{2}{*}{0.133} \\
\hline & & 48.9 & 51.1 & \\
\hline & \multirow{2}{*}{$\geq 35$} & 3 & 0 & \\
\hline & & 100 & 0 & \\
\hline \multirow{4}{*}{ Pendidikan } & \multirow{2}{*}{$\underline{\text { Dasar }}$} & 4 & 6 & \multirow{2}{*}{0.310} \\
\hline & & 40 & 60 & \\
\hline & \multirow{2}{*}{ Menengah } & 22 & 18 & \\
\hline & & 55 & 45 & \\
\hline \multirow{2}{*}{ Pekerjaan } & \multirow{2}{*}{ Kerja } & 7 & 4 & \multirow{2}{*}{0.298} \\
\hline & & 63.6 & 36.4 & \\
\hline & Tidak kerja & 1948.7 & 20 & \\
\hline
\end{tabular}




\begin{tabular}{ccccc}
\hline & & 51.3 & \\
\hline \multirow{2}{*}{ Paritas } & 1 & 9 & 17 & 0.011 \\
& & 34.6 & 65.4 & \\
\hline \multirow{2}{*}{ Pengetahuan } & & 17 & 7 & \\
& & 70.8 & 29.2 & 0.004 \\
& Baik & 22 & 11 & 0.133 \\
& & 66.7 & 33.3 & 13 \\
\hline
\end{tabular}

Dari hasil uji statistic didapati tidak ada hubungan yang bermakna antara variable individu berupa usia ( $p$ 0.133), pendidikan ( $p$ 0.310), dan pekerjaan ( $p$ 0.298) dengan motivasi pasien dalam melakukan IMD.

Hal ini sejalan dengan penelitian tentang faktor yang berhubungan dengan praktik IMD dimana pada variable usia, pekerjaan dan pendidikan didapati tidak ada hubungan antara variable usia (p 0.92) dan pendidikan (p 0.38) dengan praktik IMD (Mujur A. et al., 2014).

Hal ini juga sejalan dengan penelitian mengenai profil ibu dan peran bidan pada praktik Inisiasi Menyusu Dini (IMD) dimana didapati varibel usia ( $p$ 0.369), pekerjaan ( $p$ 0.314), dan pendidikan ( p 0,216) tidak memiliki hubungan bermakna dengan praktik Inisiasi Menyusu Dini di Kabupaten Kendal, Jawa Tengah (Raharjo BB, 2014)

Sebuah penelitian systematic review mengenai factor yang berhubungan dengan Inisiasi Menyusu Dini (IMD) didapati variable usia tidak berhubungan dengan pelaksanaan Inisiasi Menyusu Dini (IMD) (Maria T \& Regina P., 2014). Meskipun begitu usia yang terlalu muda $<16$ tahun atau pun terlalu tua $>40$ tahun meningkatkan resiko terjadinya komplikasi persalinan yang dapat mengakibatkan komplikasi baik pada ibu ataupun bayi sehingga sulit dalam melakukan praktik IMD. Komplikasi yang dapat di temui berupa persalinan pretem, bayi makrosomia, dan kehamilan ganda sehingga pada ibu usia terlalu muda ataupun tua dikategorikan sebagai kehamilan yang memnbutuhkan rujukan untuk konsultasi dana tau kerjasama dalam penanganannya.(WHO, 2013)

Pernyataan ini didukung hasil penelitian tentang faktor yang menghambat dilaksanakannya IMD di Asia Selatan salah satu nya adalah ibu yang berusia 15-19 tahun (remaja). (Sharma K Indu, 2016). Dalam penelitian ini tidak ada sampel yang berusia kurang dari 16 tahun ataupun diatas 40 tahun.

Untuk variabel tingkat pengetahuan dan paritas didapati adanya hubungan bermakna dengan motivasi ibu dalam melakukan Inisiasi Menyusu Dini (IMD) didapati nilai p 0,004 ( $p<0,05)$ untuk variabel tingkat pengetahuan dan nilai p 0,011 $(\mathrm{p}<0.05)$ untuk variabel paritas. 
Hal ini sejalan dengan penelitian tentag factor yang berhubungan dengan pelaksanaan Inisiasi Menyusu Dini di Kota Surakarta yang menyatakan tingkat pengetahuan ibu memiliki hubungan yang bermakna dengan kesediaan melakukan Inisiasi Menyusu Dini(IMD) dengan nilai $\mathrm{p}$ 0,000 (Wiendarto S., 2014). Hal ini juga sejalan dengan penelitian dengan uji regresi linear tentang factor yang berkontribusi terhadap Inisiasi Menyusu Dini (IMD) yang menyatakan bahwa variabel yang paling berhubungan terhadap implementasi Inisiasi Menyusu Dini (IMD) diantara variabel yang diteliti adalah sikap ibu ( r 0,569), kemudian pengetahuan ibu ( $r$ 0,403) dan peran bidan (0.362) (Ariyani D \& Handayani L., 2015).

Namun hal ini tidak sejalan dengan pernyataan bahwa tingkat pendidikan berhubungan terhadap tingkat pengetahuan sehingga dapat mempengaruhi tindakan dan atau perilaku. (Notoatmodjo, 2003) Dimana pada penelitan ini didapati tidak ada hubungan yang bermakna antara tingkat pendidikan dan motivasi ibu dalam melakukan Inisiasi Menyusu Dini.

Hal ini mungkin disebabkan pengetahuan tentang pentingnya inisiasi menyusu dini dan bagaimana cara melakukannya tidak didapat saat pendidikan. Informasi tersebut lebih banyak didapat dari tenaga kesehatan ataupun sesama ibu hamil saat Ante Natal care dan saat menghadiri kelas ibu hamil. Pada variabel paritas didapati hubungan yang bermakna dengan motivasi melakukan IMD dengan nilai p 0.011 .

Sejalan dengan hasil penelitian tentang faktor yang berhubungan dengan pelaksanaan IMD di Kabupaten Majalengka didapati hubungan yang bermakna antara variabel paritas dengan pelaksanaan IMD dengan nilai p 0.002. Ibu dengan jumlah paritas lebih dari satu memiliki kesempatan lebih banyak terpapar pada Ante Natal Care dan Kelas Ibu Hamil dari pada ibu kehamilan pertama. Sejalan dengan hasil penelitian didapati adanya hubungan antara keberhasilan ASI eksklusif dengan dengan keterlibatan ibu menyusui dengan kelompok pendamping ASI (Purwati Y., 2015).

\section{KESIMPULAN}

Berdasarkan hasil penelitian dari faktor faktor variabel individu yang diteliti didapati ada hubungan yang bermakna antara variabel tingkat pengetahuan dan paritas terhadap motivasi ibu dan tidak ada hubungan yang bermakna antara variabel usia, pendidikan, dan pekerjaan terhadap motivasi ibu dalam melaksanakan IMD. 


\section{DAFTAR PUSTAKA}

Ariyani D, Handayani L.(2015)Contribution Factor on Early Initiation of Breastfeeding. International Journal of Public Health Sience. Vol 4 No 3.

Bigelow A, Power M, MacLellan-Peters J, Alex M, McDonald C. (2012). Effect of Mother/Infant Skin to Skin Contact on Postpartum Depressive Symptom and Maternal Physiologicall Stres Journal of Obstetric, Gynecologic, and Neonatal Nursing Vol 41 No 3.

Direktorat Gizi Masyarakat DitJen KesMas. (2018). Pemantauan Status Gizi Tahun 2017. Kementrian Kesehatan Republik Indonesia.

Edmond et all. (2006). Delayed Breastfeeding Initiation Increase Risk of Neonatal Mortality Rate. PubMed Central.

Fikawati S dan Syafiq A.(2010). Kajian Implementasi dan Kebijakan Air Susu Ibu Eksklusif dan Inisiasi Menyusu Dini (IMD) di Indonesia. Jurnal Kesehatan Vol 14, No 1.

Kemenkes RI. (2017) Profil Kesehatan Indonesia tahun 2016. Kementrian Kesehatan Republik Indonesia.

Maria T, Regina P. (2014). Factors Associated to Breastfeeding in The First Hour of Life : Systematic Review. PubMed Central.

Mujur A, Suyani A, Idris I.(2014). Faktor Keberhasilan Inisiasi Menyusu Dini (IMD) di Puskesmas Jumpandang Baru. Program Pasca Sarjana Universitas Hasanudin Makasar.

Notoatmodjo, Soekidjo. (2003). Pendidikan dan Perilaku Kesehatan.Rineka Cipta Jakarta

Purwati,Y. (2015) Korelasi Partisipasi Ibu Menyusui pada Kelompok Pendamping ASI dengan Keberhasilan Pemberian ASI Eksklusif. Jurnal Kebidanan. Vol 11, No 1.

Raharjo BB. Profil Ibu dan Peran Bidan Dalam Praktik Inisiasi Menyusu Dini dan Asi Eksklusif. (2014). Jurnal Kesehatan Masyarakat Vol 10, No1.

Rompis O, Tumurang MN, Raule JH. (2017). Faktor- Faktor yang Berhubungan dengan Inisisasi Menyusu Dini di Rumah Sakit Siloam. Community Health Journal. Vol 2 No 1.

Sharma K Indu, Early Initiation of Breastfeding: (2016). A Systematic Literature Review of Factors and Barriers in South Asia. BMC Medicine Journal.

Suryani D, Simbolon D, ett all. (2017). Determinants Failure of Exclusive Brestfeeding on Health In The City Bengkulu. Jurnal Kesehatan Masyarakat Vol 12, No 2

Unicef. (2017) Looking abead: Child Survival and Sustainable Development Goals. UNICEF.

WHO dan UNICEF. (2018)Capture The Moment : Early Initiation of breastfeeding, best start for every newborn. World Health Organization. 
WHO, POGI, IBI. (2013.) Pelayanan Kesehatan Ibu di Fasilitas Kesehatan Dasar dan Rujukan. Kementrian Kesehatan Republik Indonesia Pedoman Bagi Tenaga Kesehatan.

Wiendarto Sigit. (2014). Hubungan Antara Pengetahuan Ibu, Motivasi Ibu, dan Dukungan Bidan dengan Kesediaan Ibu Melakukan Inisiasi Menyusu Dini (IMD). Universitas Muhammadiyah Surakarta.

Yuwansyah, Y.(2015). Faktor Faktor Yang Berhubungan dengan Pelaksanaan Inisiasi Menyusu Dini (IMD) Pada Ibu Bersalin di Wilayah Kerja Puskesmas Cigasong Kabupaten Majalengka. Midwife Journal. Vol 3, No 1. 